\title{
IMPLEMENTATION OF COLLABORATIVE AND COOPERATIVE METHODS TO STIMULATE CREATIVITY OF POSYANDU CADRES
}

\author{
Tita Hariyanti \\ Department of Public Health, Faculty of Medicine, \\ University of Brawijaya
}

\begin{abstract}
BACKGROUND: Integrated health posts (Posyandu) are on the cutting edge of the health care system. Posyandu cadres are expected to delivery health information. They are also expected to have high creativity in delivering health information so that community members can understand the information easily. Collaborative and cooperative learning methods are methods that enhance learning by peer interaction. Both techniques favor small-group with active student participation over passive, lecture-based teaching. Students are required to complete a specific task. In collaborative learning, students are assumed to already have the necessary social skills. The learning process builds on the existing skills in order to reach learning objectives. Students organize and negotiate efforts themselves. In cooperative learning students receive training in small group social skills. Activities are structured with each student having a specific role. The teacher observes, listens and intervenes in a group when necessary. Choice of these approaches depends on the academic maturity of the students. The structured cooperative learning style is more suitable for foundational knowledge typified in the lower education. The laissez faire approach of collaborative learning is more suitable for higher level content typified in the higher education. This study aimed to examine the effectiveness of collaborative and cooperative methods to stimulate the creativity of posyandu cadres.
\end{abstract}

SUBJECT AND METHODS: This was a qualitative, observational, and descriptive study. Training with collaborative and cooperative methods was conducted in Kepanjen district, Malang. It was attended by 100 posyandu cadres. A set of materials covering topics such as the elderly, stroke, and cadre role in the prevention of stroke, was given to posyandu cadres. Observation and video recording were made during the training. The dependent variable was creativity.

RESULTS: Collaborative and cooperative methods were used in the discussion to achieve the learning objectives. There were three scenarios for the discussion that aimed to bring insight to the posyandu cadres. At the end of the training, creativity of cadres seemed to emerge. Acronym was made by themselves to ease the tasks of cadres and to remember. SEHAT (healthy) was an acronym for balanced diet, rid of cigarettes, avoid stress, blood pressure regulation, regular exercise, and rest to prevent stroke. Other cadres made acronym of STROKE for stress, high blood pressure, smoking, cholesterol, emotion. STROKE acronym is also created to remind of stroke treatment. 
CONCLUSSION: Collaborative and cooperative methods can be used to enhance the creativity of posyandu cadres.

Keywords: collaborative and cooperative methods, posyandu cadres, creativity 